Document downloaded from:

http://hdl.handle.net/10251/79377

This paper must be cited as:

López-Paz, JL.; Catalá-Icardo, M.; Antón Garrido, B. (2009). Determination of diquat by flow injection-chemiluminescence. Analytical and Bioanalytical Chemistry. 394(4):1073-1079. doi:10.1007/s00216-009-2609-z.

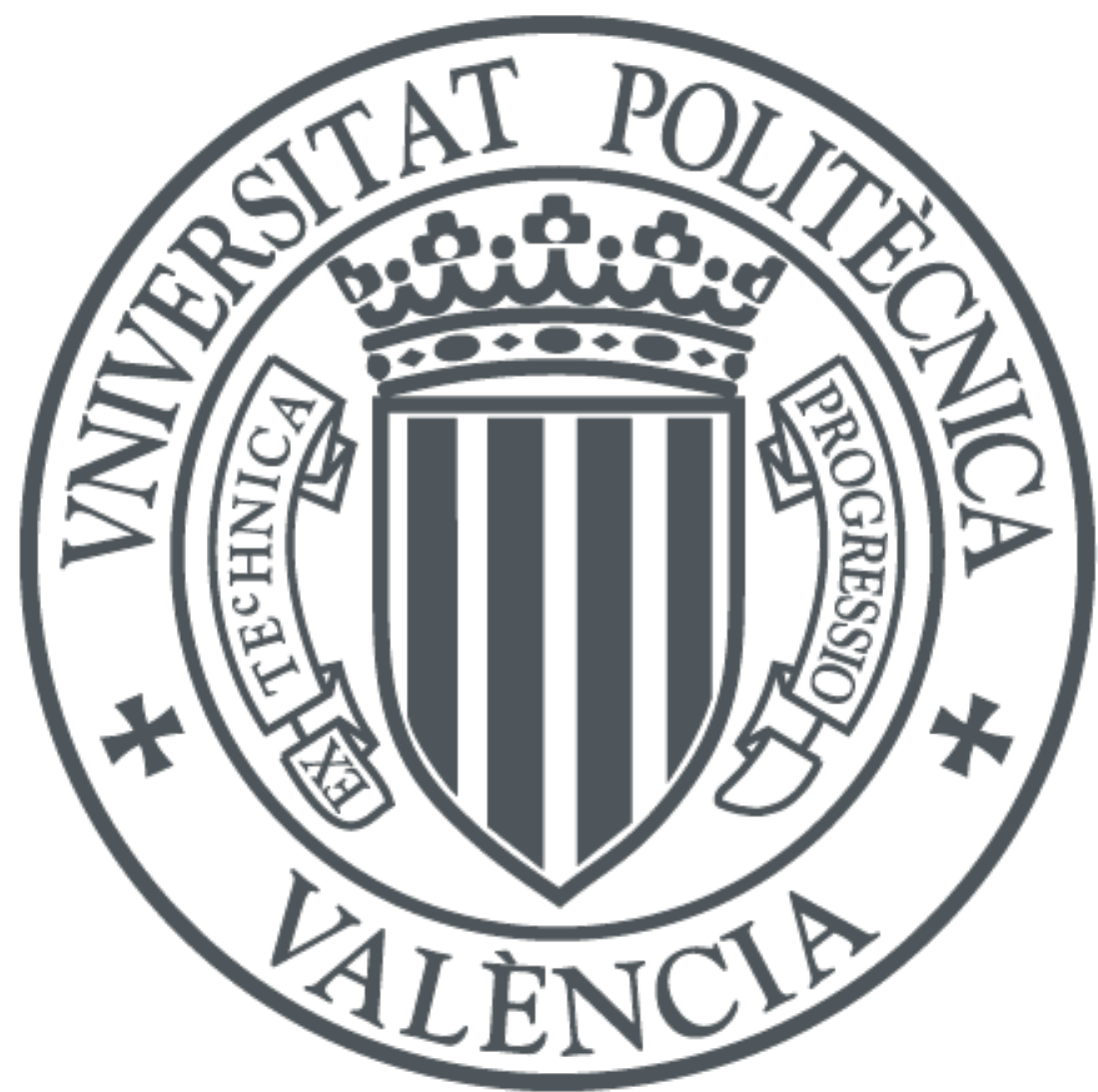

The final publication is available at

http://dx.doi.org/10.1007/s00216-009-2609-z

Copyright Springer Verlag (Germany)

Additional Information 


\title{
DETERMINATION OF DIQUAT BY FLOW INJECTION-CHEMILUMINESCENCE
}

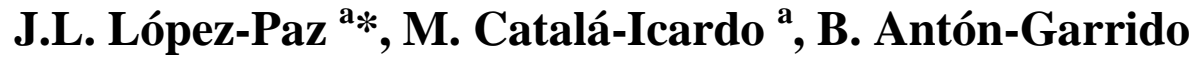 \\ * Corresponding author.Tel: ++34962849328; fax: ++34962849309. \\ E-mail address: jolopa@qim.upv.es
}

${ }^{a}$ Integrated Coastal Management Research Institute, Higher Polytechnic School of Gandía, Polytechnic University of Valencia, Carretera de Nazaret- Oliva s/n, Grao de Gandía, 46730 Gandía, Valencia, Spain.

\section{ABSTRACT}

A simple, economic, sensitive and rapid method for the determination of the pesticide diquat was described. This new method was based on the coupling of FIA methodology and direct chemiluminescent detection; to the authors knowledge this approach had not been used up to now with this pesticide. It was based on its oxidation with ferricyanide in alkaline medium; significant improvements in the analytical signal were achieved by using high temperatures and quinine as sensitizer. Its high throughput $\left(144 \mathrm{~h}^{-1}\right)$, together with its low limit of detection (2 $\mathrm{ng} \mathrm{mL} \mathrm{m}^{-1}$ ), achieved without need of preconcentration steps, permitted the reliable quantification of diquat over the linear range of (0.01-0.6) $\mu \mathrm{g} \mathrm{mL}^{-1}$ in samples from different origins (river, tap, mineral and ground waters), even in the presence of a 40-fold concentration of paraquat, pesticide commonly present in the commercial formulations of diquat.

Author Keywords: Chemiluminescence; flow injection; diquat; pesticides; water.

\section{Introduction}

Diquat [1,1'-ethylene-2,2'-bipyridylium ion] (molecular structure in figure 1) is a quickacting contact herbicide and plant desiccant. It is used to control floating and submerged weeds in waters and for preharvest desiccation. Exposure to mists of this compound may 
produce irritation of skin, mouth and upper respiratory tract, cough, chest pain and nosebleeds. Poisoning by diquat can cause acute renal failure, toxic liver damage, respiratory difficulty and brain hemorraghe. Notwithstanding, it is among the most used pesticides for weed control and it is formulated as dust or as $50 \%$ solution in water with non-ionic surface actives agents. It is available as water-soluble granules containing $2.5 \%$ diquat and $2.5 \%$ paraquat [1]. When it is released into the environment diquat rapidly adheres strongly to soil particles, which protects it from microbiological degradation, increasing the contamination risk [2].

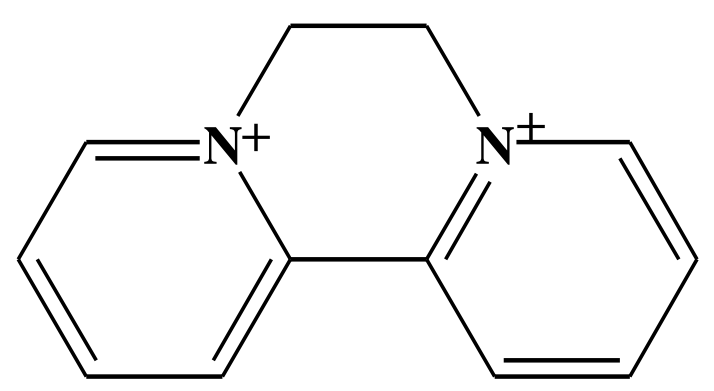

Fig.1 Molecular structure of diquat

The standard procedure recommended for this substance by the AOAC (Official Methods of Analysis) in pesticide formulations is spectrophotometric [3] but it is time consuming and their sensitivity is low. Most of the recently published methods for diquat determination are based on liquid [4-9] and gas chromatography [10], but despite of their high selectivity and sensitivity, all of them require highly expensive reagents and instrumentation, moreover timeconsuming extraction and separation procedures are also necessary, which make these methods not appropriate for routine analysis. Analyses based on voltammetry have been also performed for diquat determination; in one of them [11] square wave voltammetry was employed, but the limit of detection was an order of magnitude more than the obtained in the herein reported method. The same authors improved the sensitivity by using the multiple square wave voltammetry technique [12], but a stream of nitrogen for 10 minutes was necessary before each experiment, which increased considerably the cost and time of analysis. The capillary electrophoresis technique has some advantages such as high separation efficiency and small consumption of expensive reagents and toxic solvents, but the small volumes typically injected limits its sensitivity, which usually needs to be enhanced by introducing a sample enrichment step [13-15].

Flow Injection Analysis (FIA) methodology is an important alternative to more complex procedures due its simplicity in experimental procedure, low cost and short duration of the 
analysis. Several FIA methods have been applied to diquat determination in waters; in the most recently reported [16] low detection limits were achieved by using amperometric detection, but it was necessary to process big volumes of water through a cation exchange resin in order to retain the pesticide in its cationic form, which resulted in small sample throughputs. Spectrofluorimetric [17-18] detection have been also employed, but the dithionite solution used to reduce diquat was unstable and must be prepared freshly every 2 hours, which limited considerably the applicability of the proposed methods.

On the other hand, chemiluminescence is becoming a powerful analytical tool with widespread application in various fields owing to its high sensitivity, wide dynamic range and simple instrumentation [19]. Despite it, to the authors knowledge up to now no method based on chemiluminescence for diquat has been previously reported. Likewise, FIA techniques allow the rapid and reproducible mixing of sample and reagent near the detector, which makes this methodology particularly well suited to monitoring transient light emission from chemiluminescent (CL) reactions. The coupling of FIA techniques and CL detection has been recently used to carry out the determination of several pesticides [20-22], and with those methods low limits of detection and high throughputs were achieved.

This paper reports an economic, simple, rapid, sensitive and direct method for the determination of diquat, requiring no sophisticated equipment and fast enough for use in routine analyses, which are particularly suitable for environmental control. The proposed method is based on CL reaction between the pesticide and ferricyanide in alkaline medium by using quinine as sensitizer. It was successfully applied to the determination of diquat in samples from different origins (river, ground, tap and mineral waters).

\section{Experimental}

\section{Reagents}

All experiments were carried out by using analytical reagent grade chemicals and Milli-Q water (Millipore, Bedford, MA, USA). The reagents used were: $\mathrm{KMnO}_{4}, \mathrm{~K}_{3} \mathrm{Fe}(\mathrm{CN})_{6}, \mathrm{NaCl}$, $\mathrm{H}_{3} \mathrm{PO}_{4}$, acetone, and Triton X-100 from Panreac; $\mathrm{HNO}_{3}, \mathrm{HClO}_{4}, \mathrm{KIO}_{4}$ and $\mathrm{CeSO}_{4} \cdot 4 \mathrm{H}_{2} \mathrm{O}$ from Scharlau; $\mathrm{H}_{2} \mathrm{SO}_{4}, \mathrm{H}_{2} \mathrm{O}_{2}$, ethanol and acetonitrile from Merck; $\mathrm{NaOH}, \mathrm{HCl}$ and acetic acid from J.T. Baker; $\beta$-cyclodextrin, sodium dodecyl sulphate (SDS) and hexadecylpyridinium chloride from Fluka and rhodamine B from Sigma. Cations tested as potential inorganic interferences were prepared from chloride $\left(\mathrm{K}^{+}, \mathrm{Ca}^{2+}, \mathrm{Mg}^{2+}\right.$ and $\mathrm{Hg}^{2+}$ (Panreac); $\mathrm{Mn}^{2+}$ and $\mathrm{Fe}^{3+}$ (Scharlau)), sulfate $\left(\mathrm{Cu}^{2+}(\right.$ Panreac $\left.)\right)$ or nitrate $\left(\mathrm{Pb}^{2+}\right.$ (Panreac)) salts. Anions were obtained 
from sodium salts $\left(\mathrm{NO}_{2}{ }^{-}\right.$(Probus), $\mathrm{SO}_{4}{ }^{2-}, \mathrm{HCO}_{3}{ }^{-}, \mathrm{H}_{2} \mathrm{PO}_{4}{ }^{-}$and $\mathrm{NO}_{3}{ }^{-}$(Panreac)). Paraquat dichloride (98.5\%) (Dr. Ehrenstorfer) and urea (Scharlau) were also tested for potential interference. The chemicals tested as sensitizers were Rhodamine B (Merck), dioxane (Scharlau), 8-hydroxyquinoline (Merck), quinine hydrochloride (Sigma), fluorescein (Scharlau), formic acid (Scharlau), sodium sulfite anhydrous (Panreac) and acridine orange (Sigma).

Diquat monohydrate (99.4 \%) was supplied by Dr Ehrenstorfer. $100 \mathrm{mg} \mathrm{L}^{-1}$ stock solutions of this substance were prepared in water and stored at room temperature in the dark, then were further diluted to appropriate concentrations with water before undergoing analysis. Stability of diquat was tested by checking the absorbance of the stock solution at $310 \mathrm{~nm}$. It remained stable for at least 1 month as expected for neutral or acidic solutions [23].

A $0.005 \mathrm{M} \mathrm{Fe}(\mathrm{CN})_{6}^{3-}$ in $1 \mathrm{M} \mathrm{NaOH}$ solution was employed to carry out the oxidation of diquat. It was prepared daily from stock solutions of $0.1 \mathrm{M} \mathrm{Fe}(\mathrm{CN})_{6}{ }^{3-}$ and $2 \mathrm{M} \mathrm{NaOH}$,. Both stock solutions and a $0.05 \mathrm{M}$ quinine stock solution used as sensitizer were prepared weekly. In some cases it was necessary a sample-pretreatment to remove anionic interferences with an anionic exchange resin (IRA-400(OH) (Supelco)). The exchanger was prepared by packing an Omnifit $15 \mathrm{~cm}$ x $3 \mathrm{~mm}$ i.d. glass column with the resin.

\section{Apparatus}

The flow manifold used is depicted in figure 2 and consisted of PTFE coil of $0.8 \mathrm{~mm}$ i.d.; a Gilson (Worthington, $\mathrm{OH}$, USA) minipuls peristaltic pump provided with pump tubing from Omnifit; and a Model 161T031 valve (NResearch, Northboro, MA, USA). The flow cell was a flat-spiral quartz tube of $1 \mathrm{~mm}$ i.d. and $3 \mathrm{~cm}$ total diameter backed by a mirror for maximum light collection. The photodetector package was a P30CWAD5 type 9125B photomultiplier tube supplied by Electron Tubes; it was located in a laboratory-made light-tight box to avoid light input. The output was fed to a computer equipped with a counter-timer, also supplied by Electron Tubes.

In order to test the effect of photodegradation, a photoreactor was added. It consisted of a $400 \mathrm{~cm}$ length and $0.8 \mathrm{~mm}$ i.d. PTFE tubing helically coiled around a $15 \mathrm{~W}$ low-pressure mercury lamp (Sylvania) for germicidal use. 


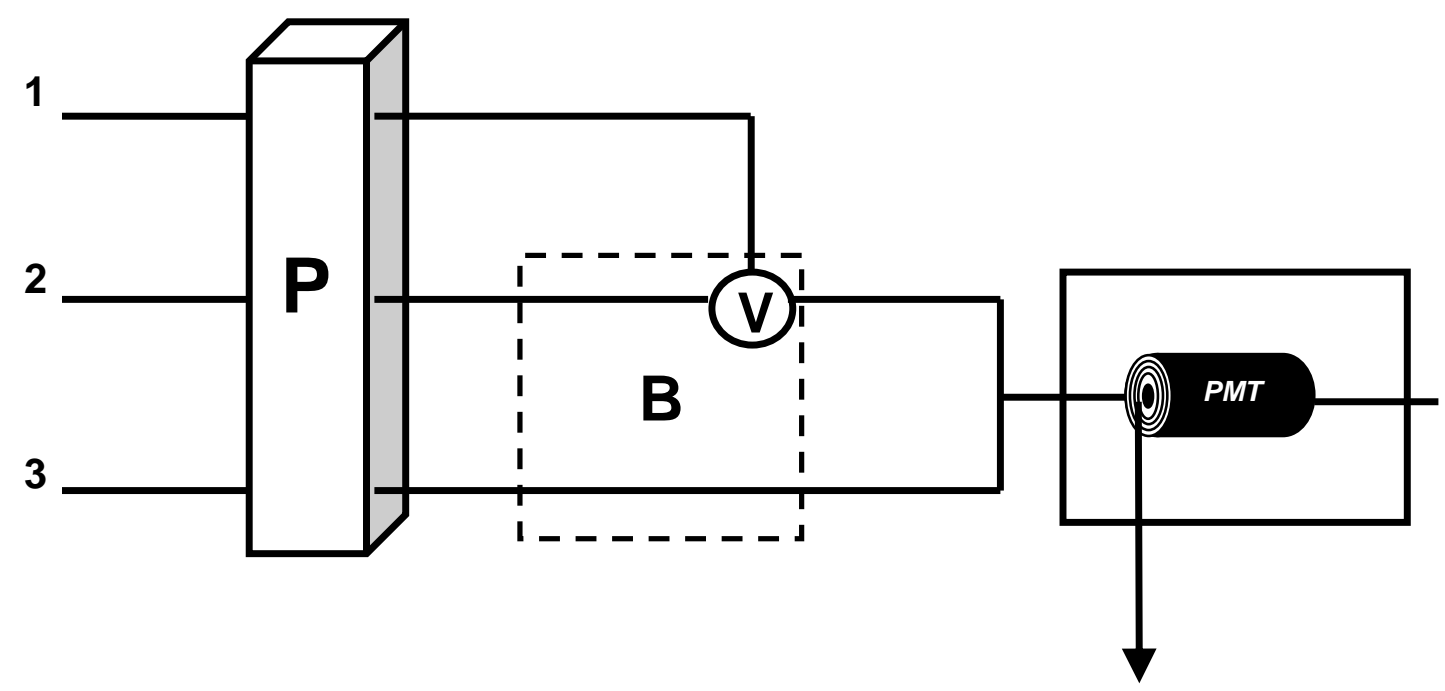

Fig. 2 Schematic diagram for the optimized flow assembly.

1: Diquat in quinine sulfate $5 \times 10^{-5} \mathrm{M}$

2: Water $\left(12 \mathrm{~mL} \mathrm{~min}^{-1}\right)$

3: $\mathrm{Fe}(\mathrm{CN})_{6}^{3-} 5 \times 10^{-3} \mathrm{M}$ in $\mathrm{NaOH} 1 \mathrm{M}\left(3 \mathrm{~mL} \mathrm{~min}^{-1}\right)$

P: Pump; V: Injection Valve (inserted volume: $411 \mu \mathrm{l}$ ); PMT: Photomultiplier tube B: Water bath; W: Waste.

Experiments were performed at $70{ }^{\circ} \mathrm{C}$ by using a water bath in which sample (loop of $175 \mathrm{~cm}$ ) and oxidant and carrier streams $(1 \mathrm{~m})$ were immersed.

\section{Sample preparation}

Ground and river waters, were freshly collected in plastic flasks and immediately filtered with polyamide membrane filters of $0.45 \mu \mathrm{m}$ to remove the suspended solid matter (for tap and mineral waters filtration was not necessary) and stored protected from light at $4{ }^{\circ} \mathrm{C}$ in the refrigerator. They were used within one week. In some cases it was necessary to remove anionic interferences by passage the sample, previously spiked with the pesticide, through an anionic-exchange resin

\section{Results and discussion}

\section{Preliminary study}

Different oxidant systems usually employed in methods based on direct chemiluminescence were tested in order to obtain CL emission from diquat. This study was carried out at room temperature using the flow assembly depicted in the figure 2 , but channel 1 of the manifold was splitted into two lines, one of which was used to test the effect of different media. The tested oxidants were $5 \times 10^{-4} \mathrm{M} \mathrm{KMnO}_{4}, \mathrm{Ce}(\mathrm{IV})$ and $\mathrm{KIO}_{4}$ in $0.5 \mathrm{M} \mathrm{H}_{2} \mathrm{SO}_{4}$ and $5 \times 10^{-4} \mathrm{M} \mathrm{KIO}_{4}$, 
$\mathrm{H}_{2} \mathrm{O}_{2}$ and $\mathrm{K}_{3} \mathrm{Fe}(\mathrm{CN})_{6}$ in $0.5 \mathrm{M} \mathrm{NaOH}$. With this aim, a $100 \mathrm{mg} \mathrm{L}^{-1}$ diquat solution was mixed alternatively with $0.1 \mathrm{M} \mathrm{H}_{2} \mathrm{SO}_{4}, 0.1 \mathrm{M} \mathrm{NaOH}$ and water. As it was previously known that diquat is photochemically decomposed by UV radiation [23], pesticide insertions were performed with and without previous irradiation in order to check its effect, provided that its positive effect on the CL emission have been widely reported [24]. With this aim, the resulting mixture was propelled through a PTFE tube helically coiled around a UV lamp placed on-line. After $40 \mathrm{~s}$ of irradiation it was injected into a carrier of water. The carrier solution merged with the oxidant solution into a T-piece connected to the flow-cell. The obtained results are summarised in table 1.

As can be observed the CL signals clearly increased when $\mathrm{K}_{3} \mathrm{Fe}(\mathrm{CN})_{6}$ in alkaline medium was the oxidant, likewise no improvement was achieved by using the photodegradation step when this oxidizing agent was used, to the contrary, the analytical signal decreased significantly.

Because of that, it was decided to carry out the oxidation of diquat without previous UV irradiation and the selected oxidant system was $\mathrm{K}_{3} \mathrm{Fe}(\mathrm{CN})_{6}$ in alkaline medium.

The effect of media in which the pesticide was inserted was also investigated, bearing in mind that diquat readily hydrolyses in alkaline solutions [23]. Hence, a $1 \mu \mathrm{g} \mathrm{mL} \mathrm{m}^{-1}$ solution of diquat was alternatively mixed with water, three solutions of $\mathrm{H}_{2} \mathrm{SO}_{4}(0.01,0.1$ and $0.5 \mathrm{M})$, and three solutions of $\mathrm{NaOH}(0.01,0.1$ and $0.5 \mathrm{M})$, which provided a strong acid and alkaline media, respectively. The analytical signal decreased by $50 \%$ when the mixing took place with $0.5 \mathrm{M}$ $\mathrm{NaOH}$. A slight increase in the CL signal was obtained when the pesticide was mixed with 0.5 $\mathrm{M} \mathrm{H}_{2} \mathrm{SO}_{4}$, no significant changes were observed in the other cases. These results clearly demonstrated that the products resulting from alkaline hydrolysis of diquat did not provide any improvement. As the slight increase in CL signal observed for the highest acidic concentration assayed was assumed to come from its influence on the oxidation reaction, it was decided to carry out the diquat insertions in water. Because of that, it was unnecessary to put an additional channel to introduce the media, increasing in this way the sensitivity by avoiding unnecessary dilutions 
Table 1. Effect of oxidizing agents on the CL signal of $100 \mu \mathrm{g} \cdot \mathrm{mL}^{-1}$ diquat.

\begin{tabular}{|c|c|c|c|c|}
\hline $\begin{array}{c}\text { Oxidizer } \\
\left(5 \times 10^{-4} \mathrm{M}\right)\end{array}$ & $\begin{array}{c}\text { Oxidation } \\
\text { medium }\end{array}$ & Pesticide medium $^{a}$ & $\operatorname{Lamp}^{b}$ & Signal (kHz) \\
\hline \multirow{6}{*}{$\mathrm{MnO}_{4}^{-}$} & \multirow{6}{*}{$0.5 \mathrm{M} \mathrm{H}_{2} \mathrm{SO}_{4}$} & \multirow{2}{*}{ Water } & ON & 0.118 \\
\hline & & & $\mathrm{OFF}$ & 0.079 \\
\hline & & \multirow{2}{*}{$0.1 \mathrm{M} \mathrm{H}_{2} \mathrm{SO}_{4}$} & $\mathrm{ON}$ & 0.129 \\
\hline & & & $\mathrm{OFF}$ & 0 \\
\hline & & \multirow{2}{*}{$0.1 \mathrm{M} \mathrm{NaOH}$} & $\mathrm{ON}$ & 0.171 \\
\hline & & & $\mathrm{OFF}$ & 0 \\
\hline \multirow{6}{*}{$\mathrm{Ce}(\mathrm{IV})$} & \multirow{6}{*}{$0.5 \mathrm{M} \mathrm{H}_{2} \mathrm{SO}_{4}$} & \multirow{2}{*}{ Water } & $\mathrm{ON}$ & 0.223 \\
\hline & & & $\mathrm{OFF}$ & 0 \\
\hline & & \multirow{2}{*}{$0.1 \mathrm{M} \mathrm{H}_{2} \mathrm{SO}_{4}$} & $\mathrm{ON}$ & 1.031 \\
\hline & & & OFF & 0.053 \\
\hline & & \multirow{2}{*}{$0.1 \mathrm{M} \mathrm{NaOH}$} & $\mathrm{ON}$ & 1.216 \\
\hline & & & $\mathrm{OFF}$ & 0 \\
\hline \multirow{6}{*}{$\mathrm{IO}_{4}^{-}$} & \multirow{6}{*}{$0.5 \mathrm{M} \mathrm{H}_{2} \mathrm{SO}_{4}$} & \multirow[t]{2}{*}{ Water } & $\mathrm{ON}$ & 0 \\
\hline & & & $\mathrm{OFF}$ & 0 \\
\hline & & \multirow{2}{*}{$0.1 \mathrm{M} \mathrm{H}_{2} \mathrm{SO}_{4}$} & $\mathrm{ON}$ & 0.400 \\
\hline & & & $\mathrm{OFF}$ & 0 \\
\hline & & \multirow{2}{*}{$0.1 \mathrm{M} \mathrm{NaOH}$} & $\mathrm{ON}$ & 0 \\
\hline & & & $\mathrm{OFF}$ & 0 \\
\hline \multirow{6}{*}{$\mathrm{IO}_{4}^{-}$} & \multirow{6}{*}{$0.5 \mathrm{M} \mathrm{NaOH}$} & \multirow{2}{*}{ Water } & $\mathrm{ON}$ & 0 \\
\hline & & & OFF & 0 \\
\hline & & \multirow{2}{*}{$0.1 \mathrm{M} \mathrm{H}_{2} \mathrm{SO}_{4}$} & $\mathrm{ON}$ & 0.084 \\
\hline & & & OFF & 0 \\
\hline & & \multirow{2}{*}{$0.1 \mathrm{M} \mathrm{NaOH}$} & $\mathrm{ON}$ & 4.897 \\
\hline & & & $\mathrm{OFF}$ & 0.056 \\
\hline \multirow{6}{*}{$\mathrm{Fe}(\mathrm{CN})_{6}{ }^{3-}$} & \multirow{6}{*}{$0.5 \mathrm{M} \mathrm{NaOH}$} & \multirow{2}{*}{ Water } & $\mathrm{ON}$ & 30.801 \\
\hline & & & $\mathrm{OFF}$ & 132.978 \\
\hline & & \multirow{2}{*}{$0.1 \mathrm{M} \mathrm{H}_{2} \mathrm{SO}_{4}$} & $\mathrm{ON}$ & 0.431 \\
\hline & & & OFF & 136.659 \\
\hline & & \multirow{2}{*}{$0.1 \mathrm{M} \mathrm{NaOH}$} & $\mathrm{ON}$ & 11.783 \\
\hline & & & OFF & 140.053 \\
\hline \multirow{6}{*}{$\mathrm{H}_{2} \mathrm{O}_{2}$} & \multirow{6}{*}{$0.5 \mathrm{M} \mathrm{NaOH}$} & \multirow{2}{*}{ Water } & $\mathrm{ON}$ & 0.089 \\
\hline & & & $\mathrm{OFF}$ & 0.007 \\
\hline & & & $\mathrm{ON}$ & 0.226 \\
\hline & & $0.1 \mathrm{M} \mathrm{H}_{2} \mathrm{SO}_{4}$ & OFF & 0.141 \\
\hline & & & $\mathrm{ON}$ & 5.937 \\
\hline & & U.1 vi NauH & OFF & 0.060 \\
\hline
\end{tabular}

${ }^{\text {a }}$ Pesticide solution was merged with the corresponding media immediately before injection

${ }^{\mathrm{b}}$ Diquat solution was irradiated $40 \mathrm{~s}$ with UV light prior injection. 


\section{Optimisation}

\section{Influence of the oxidant concentration and medium on the redox reaction}

The effect of ferricyanide concentration on $1 \mu \mathrm{g} \mathrm{mL} \mathrm{m}^{-1}$ diquat $\mathrm{CL}$ was studied over the range $\left(5 \times 10^{-5}-5 \times 10^{-3}\right) \mathrm{M}$ introducing in all cases the oxidant into the manifold together with $0.5 \mathrm{M}$ $\mathrm{NaOH}$. It was observed that the signal remained virtually constant between $5 \times 10^{-4}$ and $3 \times 10^{-3}$ M. Thus, a value of $2 \times 10^{-3} \mathrm{M}$ was selected for subsequent investigations.

The effect of the medium in which the oxidation reaction took place was also investigated by changing the concentration of $\mathrm{NaOH}$ in ferricyanide solutions over a wide range comprised between 0.01 and $2 \mathrm{M}$. In view of the obtained results for a $1 \mu \mathrm{g} \mathrm{mL}^{-1}$ diquat solution, shown in figure 3, the preselected $\mathrm{NaOH}$ concentration was $0.4 \mathrm{M}$. Given the strong influence of this parameter on the analytical signal, it was reoptimized at the end of the optimization process, but no changes were observed; thus the above mentioned value was finally chosen.

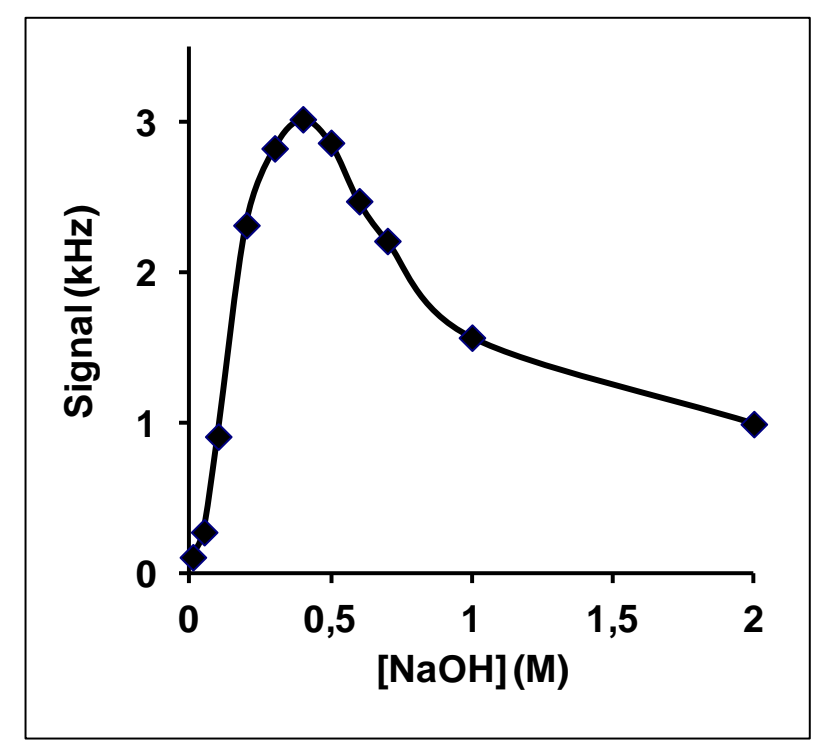

Fig. 3 Effect of the basic medium on the oxidant reaction

\section{Effect of chemiluminescence enhancers and organized media}

Most CL reactions have low quantum efficiency and require the addition of a sensitizer. The effect of some common enhancers on the CL reaction was investigated by mixing a solution containing $5 \times 10^{-5} \mathrm{M}$ (for formic acid a value of $0.1 \mathrm{M}$ was assayed), of the sensitizer with 1 $\mu \mathrm{g} \mathrm{mL}{ }^{-1}$ diquat immediately before injection. To this end, the channel 1 depicted in figure 2 was splitted into two lines, one of which was used to test the different enhancers.

With sulfite, 8-hydroxyquinoline, formic acid, acridine orange and fluoresceine decreases in the signal were observed. With rhodamine B no significant changes were obtained. Only with quinine the chemiluminiscence increased by $15 \%$. 
Other reagents used to promote the photodegradation of compounds, such as acetone $0.5 \%$, acetonitrile $20 \%$, acetone $0.5 \%+$ acetonitrile $20 \%$, ethanol $5 \%$ and dioxane $5 \%$, were also tested by using the procedure above described. For acetonitrile $20 \%$ an increase of $60 \%$ in the signal was achieved. Acetone $0.5 \%+$ acetonitrile $20 \%$ yielded an improvement of $20 \%$ : With the rest of substances decreases in the signal were observed.

The organised media provided by surfactants can increase the lifetime of emitting species. Hence, the influence on the CL signal of anionic (SDS), cationic (hexadecylpiridinium chloride) and neutral (Triton X-100) surfactants was studied by using $1 \mu \mathrm{g} \mathrm{mL} L^{-1}$ diquat solutions. Concentrations corresponding to 2-fold and 4-fold critical micellar concentrations were assayed by using the manifold above described but no changes in the signal were observed. $\beta$-cyclodextrin was also tested at 2 different concentrations (0.46 and $0.95 \%)$, bearing in mind that it may enhance CL intensity by protection of the excited state via hostguest interactions, but the signal was not significantly improved either.

A more complete study about the influence of quinine and acetonitrile was carried out by changing their concentrations over the ranges $\left(5 \times 10^{-7}-2 \times 10^{-3}\right) \mathrm{M}$ and (5-20)\% for quinine and acetonitrile, respectively. The best improvements were achieved for $10^{-4} \mathrm{M}$ quinine $(+50 \%)$ and $20 \%$ acetonitrile $(+60 \%)$. In order to check if additional increases in the signal were achieved when both enhancers were together, the acetonitrile concentration was varied from 5 to $20 \%$ in a solution containing $10^{-4} \mathrm{M}$ quinine and the quinine concentration was changed over the range $\left(5 \times 10^{-5}-5 \times 10^{-4}\right) \mathrm{M}$ in a $20 \%$ acetonitrile solution. In all cases no significant changes were observed.

As the achieved improvements in the signal were very similar for both enhancers, quinine was selected as the optimum sensitizer, hence potential damages to tubing from acetonitrile and toxic wastes were avoided. On the other hand the use of this organic solvent would produce bubbles in case of the use of high temperatures were necessary, which would interfere considerably in the diquat determination. As quinine did not affect the stability of the pesticide, both substances were introduced by using the same stream, hence the selected value for quinine concentration in the channel 1 depicted in figure 2 was $5 \times 10^{-5} \mathrm{M}$.

\section{Influence of the temperature}

The effect of the temperature on the redox reaction was studied over the range $22-90{ }^{\circ} \mathrm{C}$ by using $0.5 \mu \mathrm{g} \mathrm{mL}{ }^{-1}$ of diquat. This study was carried out by immersing the loop $(175 \mathrm{~cm})$ together with $1 \mathrm{~m}$ of the carrier and oxidant streams in a water bath located immediately before the injection valve in order to avoid an unnecessary dispersion of the sample. As can 
be observed in figure 4, when the temperature was increased so do the CL signal. Despite the best results were achieved for the highest values of temperature, a value of $70{ }^{\circ} \mathrm{C}$ was selected for further work in order to avoid bubbles formation and mechanical problems in the system.

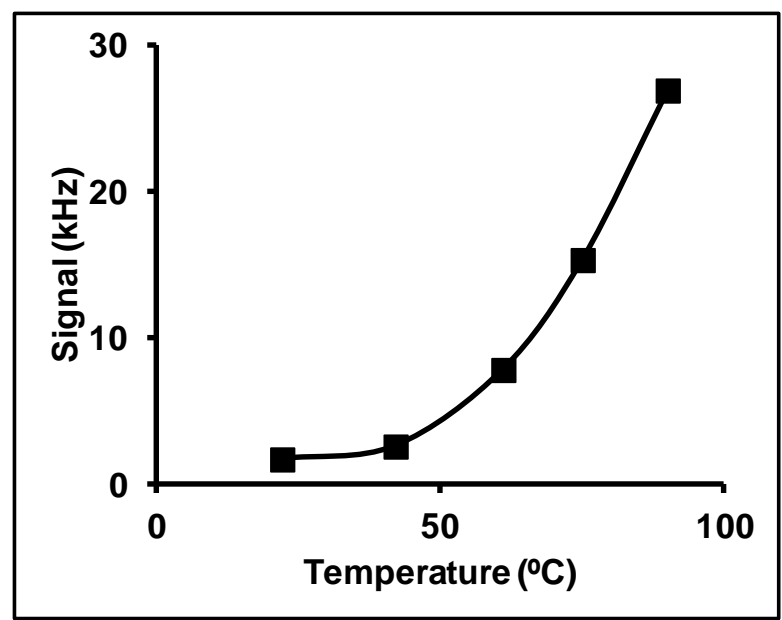

Fig. 4 Influence of the temperature on the CL signal

\section{Effect of flow rate and sample volume}

The maximum collection of the emitted light is strongly dependant on the flow rate, because of that it is an important parameter in CL detection. With the aim to study the effect of it, the total carrier and oxidant flow rate was varied from 8.5 to $19.5 \mathrm{~mL} \mathrm{~min}^{-1}$. As shown in figure 5 the flow rate increases, so do the signal provided by a solution containing $0.5 \mu \mathrm{g} \mathrm{mL}^{-1}$ of diquat, flow rates above $14 \mathrm{~mL} \mathrm{~min}^{-1}$ did not enhance significantly the CL intensity but increased the pressure in the tubes and reagents consumption. Thus, a total flow rate of $15 \mathrm{~mL}$ $\min ^{-1}$ was chosen for further investigations.

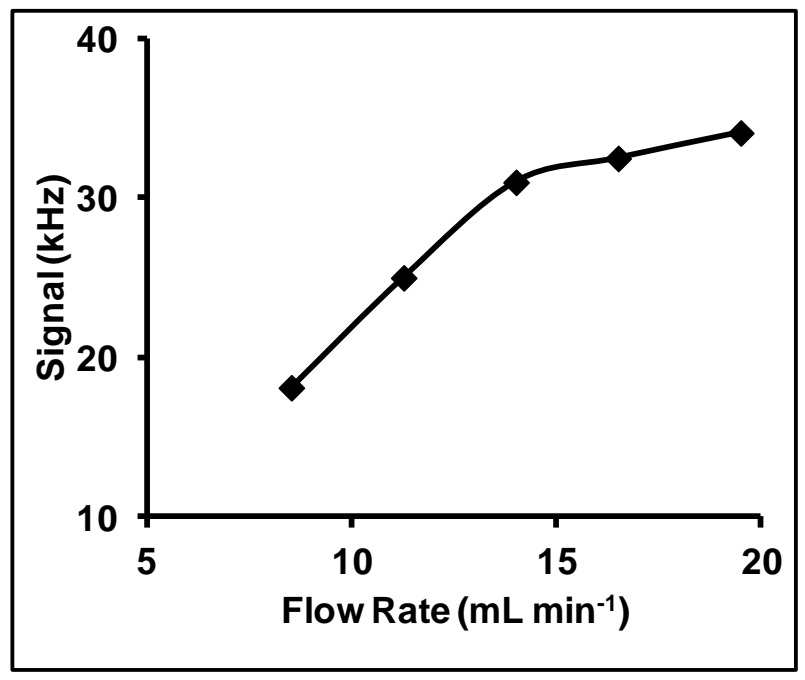

Fig. 5 Effect of the flow rate on the CL signal 
In order to increase the sensitivity of the developed method the flow-rates ratio between carrier and oxidant was changed, hence the final ratio was $4: 1$ (carrier: $12 \mathrm{~mL} \mathrm{~min}^{-1}$ and oxidant: $3 \mathrm{~mL} \min ^{-1}$ ), instead of the 1:1 ratio previously used. As a consequence of this change, the optimized concentrations of ferricyanide and $\mathrm{NaOH}$ had to be altered; their corresponding values were $5 \times 10^{-3}$ and $1 \mathrm{M}$ respectively as shown in figure 2 . After this modification in the manifold the CL signal of $0.5 \mu \mathrm{g} \mathrm{mL}^{-1}$ of diquat was increased by $70 \%$ The role of sample volume is also critical, as shown in figure 6. Above $411 \mu$ l the signal remained practically constant; this value was therefore finally chosen.

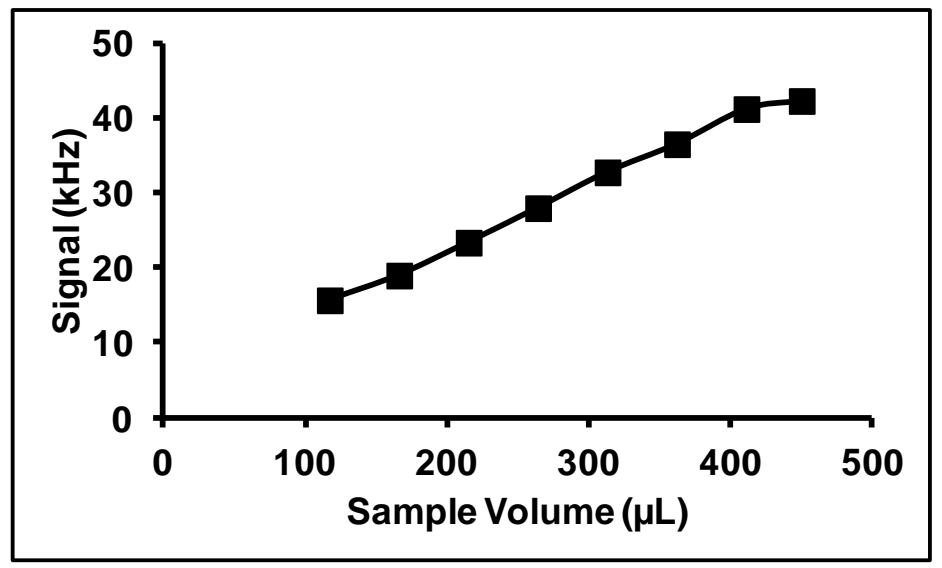

Fig. 6 Effect of the sample volume inserted on the CL signal

\section{Analytical performance}

\section{Analytica data}

The analytical performance of the method was studied with the manifold and conditions depicted in the figure 2; the obtained analytical figures of merit are summarised in table 2.

The calibration graph was constructed from seven concentrations and five replicates measurements for each. The limit of detection was taken to be the lowest diquat concentration that yielded a signal equal to the blank signal plus three times its standard deviation. The repeatability of the proposed method was determined by analysing a series of 20 standard samples containing $0.2 \mu \mathrm{g} \mathrm{mL}^{-1}$ of pesticide. Finally, the day-to-day reproducibility was performed working in five different days with freshly prepared solutions (rsd was calculated for the slopes of the linear equations). 
Table 2. Analytical figures of merit for the determination of diquat.

\begin{tabular}{|c|c|}
\hline $\begin{array}{c}\text { Linear equation }^{\mathrm{a}} \\
\left(\mathrm{I}_{\mathrm{E}} \text { in } \mathrm{kHz} \text { and } \mathrm{c} \text { in } \mu \mathrm{g} \mathrm{mL}^{-1}\right)\end{array}$ & $\begin{aligned} \mathrm{I}_{\mathrm{E}} & =85.54 \mathrm{c}-1.12 \\
\mathrm{r} & =0.9984(\mathrm{n}=7)\end{aligned}$ \\
\hline Dynamic range $\left(\mu \mathrm{g} \mathrm{mL} \mathrm{L}^{-1}\right)$ & $0.01-0.6$ \\
\hline $\operatorname{LOD}\left(\mathbf{n g ~ m L} \mathbf{L}^{-1}\right)$ & 2 \\
\hline Sample throughput $\left(\mathrm{h}^{-1}\right)$ & 144 \\
\hline Repeatability (\%) (rsd) $(\mathbf{n}=20)$ & 3.1 \\
\hline Reproducibility $^{\text {b }}(\%)($ rsd) $(n=5)$ & 6.7 \\
\hline
\end{tabular}

${ }^{\text {a }}$ Seven different diquat concentrations were used in the calibration graphs.

${ }^{\mathrm{b}}$ It was studied by preparing calibration graphs in 5 different days with fresh solutions.

\section{Interferences}

The potential interference of the most common ions in water was investigated by preparing solutions of salts containing those ions together with $0.25 \mu \mathrm{g} \mathrm{mL} L^{-1}$ of diquat. The obtained signals were tested against a pure solution of pesticide at the same concentration. Following this procedure the effects on the CL signal of urea, a common organic pollutant in environmental samples and paraquat, pesticide which is commonly formulated together with diquat, were also investigated.

A substance was considered not to interfere if it caused a relative error less than $5 \%$. The maximum tolerable tested concentrations are shown in table 3. 
Table 3. Influence of interfering compounds on $0.25 \mu \mathrm{g} \mathrm{mL}^{-1}$ diquat.

\begin{tabular}{|c|c|c|c|c|c|}
\hline Interference & $\boldsymbol{\mu g} \mathbf{~ m L}^{-\mathbf{1}}$ & $\begin{array}{c}\text { Error } \\
(\%)\end{array}$ & Interference & $\boldsymbol{\mu g} \mathbf{~ L L}^{-\mathbf{1}}$ & $\begin{array}{c}\text { Error } \\
(\%)\end{array}$ \\
\hline $\mathrm{Ca}^{2+}$ & 1000 & -0.8 & $\mathrm{SO}_{4}{ }^{2-}$ & 10000 & -1.2 \\
$\mathrm{Mg}^{2+}$ & 1000 & 1.6 & $\mathrm{NO}_{3}{ }^{-}$ & 3000 & 3.2 \\
$\mathrm{~K}^{+}$ & 100 & -1.6 & $\mathrm{HPO}_{4}{ }^{2-}$ & 3200 & -4.3 \\
$\mathrm{NH}^{+}$ & 10 & -4.1 & $\mathrm{C}_{2} \mathrm{O}_{4}{ }^{2-}$ & 2000 & 0.9 \\
$\mathrm{Fe}^{3+}$ & 1.25 & -2.4 & $\mathrm{CH}_{3} \mathrm{COO}^{-}$ & 80 & -5 \\
$\mathrm{~Pb}^{2+}$ & 0.5 & -1.8 & $\mathrm{HCO}_{3}^{-}$ & 10 & -5 \\
$\mathrm{Cu}^{2+}$ & 0.25 & 0.9 & $\mathrm{NO}_{2}{ }^{-}$ & 4 & -4.9 \\
$\mathrm{Hg}^{2+}$ & 0.25 & 4.9 & Urea & 3000 & -4.8 \\
$\mathrm{Mn}^{2+}$ & 0.05 & -1.7 & Paraquat & 10 & 2.3 \\
$\mathrm{Cl}^{-}$ & 2500 & 2.4 & & & \\
\hline
\end{tabular}

Several cations showed a strong interference; this fact was probably due to its catalytic effect either on the decomposition of diquat or on the oxidation reaction. Regarding to paraquat, it is worth taking into account that this pesticide is commonly formulated together with diquat in similar concentrations. For example, it is possible to find formulations with water-soluble granules containing $2.5 \%$ diquat and $2.5 \%$ paraquat [1], and the usual ratio paraquat/diquat in commercial formulations used in Spain [25] is 1.5. The applicability of the developed method to the analysis of diquat in waters polluted with those formulations was demonstrated, bearing in mind that it was possible to carry out determinations of diquat for ratios of paraquat/diquat as high as 40 with an error $<3 \%$.

\section{Application of the method}

The proposed method was applied to the determination of diquat in river, tap, mineral and ground water samples. Prior to analysis, the samples were spiked with a stock solution containing $5 \mu \mathrm{g} \mathrm{mL}^{-1}$ of diquat in order to obtain solutions containing 4 different pesticide concentrations, namely $0.05,0.1,0.15$ and $0.2 \mu \mathrm{g} \mathrm{mL}{ }^{-1}$ within the dynamic range of the method $\left(0.05-0.6 \mu \mathrm{g} \mathrm{mL}^{-1}\right)$. The results are summarised in table 4 . 
Table 4 Origins and recoveries of the spiked water samples

\begin{tabular}{|c|c|c|}
\hline Sample & Recovery $(\%)^{\mathbf{a}}$ & Recovery $(\%)^{\mathbf{a}, \mathbf{b}}$ \\
\hline Ground water (Villamarchante) & 100.9 & \\
\hline Tap water (Gandía) & 99.6 & \\
\hline Bohilgues river & 109.3 & 100.4 \\
\hline Mineral water (Fontvella) & 112.1 & 102.1 \\
\hline Mineral water (Lanjarón) & 78.7 & 94.9 \\
\hline
\end{tabular}

${ }^{\mathrm{a}}$ Samples were spiked with $0.05,0.1,0.15$ and $0.2 \mu \mathrm{gmL}^{-1}$ of diquat

${ }^{\mathrm{b}}$ Samples were passed through an anionic exchanger after spiking with diquat diquat

As can be observed high errors were obtained for river and mineral waters. Despite most anions were not the main interferents of the method, bicarbonate showed an important interferent effect (table 3). Because of that, and bearing in mind the high concentrations of this ion commonly present in environmental samples, it was decided to pass these samples through an off-line column containing an anion-exchange resin. The results displayed in the table 4 show that the errors were significantly reduced.

\section{Conclusions}

The proposed method for diquat determination provides higher sample throughputs (144 samples $\mathrm{h}^{-1}$ ) and it is much more simple and economic than the previously reported methods for the determination of this pesticide. The coupling of FIA methodology and CL detection had not been used up to now with diquat. FIA methodology has allowed to use reagents in small amounts without need of expensive instrumentation, which decreases not only the cost of the analysis but its environmental impact. The CL detection has permitted to achieve a low limit of detection $\left(2 \mathrm{ng} \mathrm{mL}^{-1}\right)$ without preconcentration steps; this concentration is below of the maximum contaminant level goal $\left(\mathrm{MCLG}=20 \mathrm{ng} \mathrm{mL} \mathrm{mL}^{-1}\right.$ ) set by the US Environmental Protection Agency (EPA) [26]. These features make this method particularly well suited to routine analyses of diquat in waters from different origins, even in the presence of a 40-fold concentration of paraquat, commonly present in the commercial formulations of diquat. The new method of analysis is advantageous over other diquat-FIA methods, taking into account that the achieved limit of detection is lower than the previously reported in those FIA 
procedures (6.32 $\mathrm{ng} \mathrm{mL} \mathrm{mL}^{-1}$ by using amperometric detection [16] and $7 \mathrm{ng} \mathrm{mL}{ }^{-1}$ with spectrofluorimetric detection [17]). On the other hand, those methods involved timeconsuming procedures such as preconcentration steps [16] or the use of unstable reagents which limited considerably the applicability of the methods [17-18].

\section{Acknowledgements}

The authors would like to thank Ministerio de Educación y Ciencia from Spain and FEDER for financial support. Project CTM2006-11991. 


\section{References}

1. Wayland J Hayes Jr and Edward R Laws Jr (1991) Handbook of Pesticide Toxicology.

2. http://www.epa.gov/06WDW/contaminants/dw_contamfs/diquat.html (accessed in August 2008)

3. Official Methods of analysis of AOAC International (2000) $17^{\text {th }}$ edition., AOAC International, Gaithersburg, MD, USA.

4. Hara S, Sasaki N, Takase D, Shiotsuka S, Ogata K, Futagami K, Tamura K (2007) Anal Sci 23(5): 523-531.

5. Rial Otero R, Cancho Grande B, Pérez Lamela C, Simal Gandara J, Aria Estevez M (2006) J Chromatogr Sci 44(9): 539-542.

6. Aramendia MA, Borau V, Lafont F, Marinas JM, Moreno JM, Porras JM, Urbano FJ (2006) Food Chem 97(1): 181-188.

7. Nuñez O, Moyano E, Galceran MT (2004) Anal Chim Acta 525(2): 183-190.

8. Martinez Vidal JL, Belmonte Vega A, Sanchez Lopez FJ, Garrido Frenich A J (2004) Chromatogr A 1050(2): 179-184.

9. Lee XP, Kumazawa T, Fujishiro M, Hasegawa C, Arinobu T, Seno H, Sato K (2004) J Mass Spectrom 39(10): 1147-1152.

10. De Almeida RM, Yonamine M (2007) J Chromatogr B 853(1-2): 260-264.

11. De Souza D, Machado SAS (2006) Electroanalysis 18(9): 862-872.

12. De Souza D, Da Silva MRC, Machado SAS (2006) Electroanalysis 18(23): 23052313.

13. Picó Y, Rodriguez R, Manes J (2003) Trends Anal Chem 22(3): 133-151.

14. Ishiwata $\mathrm{T}$ (2004) Bunseki Kagaku 53(8): 863-864.

15. Carneiro MC, Puignou L, Galcerán MT (2000) Anal Chim Acta 408: 263.

16. Luque M, Rios A, Valcarcel M (1998) Analyst 123(11): 2383-2387.

17. Perez Ruiz T, Martínez Lozano C, Tomas V (1991) Int J Environ Anal Chem 44(4): 243-252.

18. Perez Ruiz T, Martínez Lozano C, Tomas V (1991) Anal Chim Acta 244(1): 99-104.

19. Townshend A (1990) Analyst 115: 495-500.

20. López Paz J.L, Catalá Icardo M (2008) Anal Chim Acta, 625: 173-179

21. Pawlicová Z, Sahuquillo I, Catalá Icardo M, García Mateo JV, Martínez Calatayud J. (2006) Anal Sci 22: 29-34

22. Albert García JR, Catalá Icardo M, Martínez Calatayud J (2006) Talanta 69: 608-614

23. Tomlin CDS (1997) The Pesticide Manual. $11^{\text {th }}$ Edition. The British Crop Protection Council.

24. Catalá-Icardo M., Martínez-Calatayud J (2008) Crit. Rev. Anal. Chem., 38: 118-130.

25. http://www.marm.es/ (accessed in September 2008)

26. http://www.epa.gov/OGWWDW/contaminants (accessed in October 2008) 